\title{
Effects of subthalamic nucleus deep brain stimulation and levodopa on energy production rate and substrate oxidation in Parkinson's disease
}

\author{
Caroline Perlemoine ${ }^{1}$, Frédéric $\mathrm{Macia}^{2}$, François Tison ${ }^{2}$, Isabelle Coman ${ }^{2}$, Dominique Guehl ${ }^{2}$, \\ Pierre Burbaud $^{2}$, Emmanuel Cuny ${ }^{3}$, Laurence Baillet ${ }^{1}$, Henri Gin ${ }^{1}$ and Vincent Rigalleau ${ }^{1}$ \\ ${ }^{1}$ Service de Nutrition-Diabétologie, Hôpital Haut-Lévêque, Avenue Magellan, 33600 Pessac, France \\ ${ }^{2}$ Service de Neurologie, Hôpital Haut-Lévêque, Pessac, France \\ ${ }^{3}$ Service de Neurochirurgie, Hôpital du Tripode, Bordeaux, France
}

(Received 17 May 2004 - Revised 9 August 2004 - Accepted 4 September 2004)

\begin{abstract}
Patients with Parkinson's disease (PD) often lose weight, but after subthalamic nucleus deep brain stimulation (STN-DBS), they gain weight. We compared daily energy intake (DEI), resting energy expenditure (REE) and substrate oxidation rates (measured by indirect calorimetry) in nineteen STN-DBS-treated patients (Group S), thirteen others on pharmacologic treatment by levodopa (Group L) and eight control subjects. We also determined the acute effects of STN-DBS and levodopa on REE and substrate oxidation rates. STNDBS treated patients gained $9 \cdot 7$ (SEM 7.1) kg after surgery, whereas patients on pharmacologic treatment lost $3 \cdot 8$ (SEM 10.0) kg since diagnosis. In STN-DBS-treated patients, REE $(-16.5 \% ; P<0.001)$, lipid oxidation $(-27 \% ; P<0.05)$ and protein oxidation $(-46 \%$; $P<0.05)$ were decreased, whereas glucose oxidation was elevated $(+81 \% ; P<0.05)$ as compared to patients on pharmacologic treatment. Levodopa acutely reduced REE $(-8.3 \% ; P<0.05)$ and glucose oxidation $(-37 \% ; P<0.01)$ with a slight hyperglycaemic effect (after levodopa challenge: 5.6 (SEM 0.8) $v$. before levodopa challenge: 5.3 (SEM 0.6) mmol/l; $P<0.01$ ). Switching 'on' STN-DBS acutely reduced REE $(-17.5 \% ; P<0.01)$ and lipid oxidation $(-24 \% ; P<0.001) 30$ min after starting stimulation. Fasting glycaemia was slightly but significantly reduced $(5.4(\operatorname{SEM} 1.4)$ v. $5 \cdot 5($ SEM 1.3$) \mathrm{mmol} / \mathrm{l} ; P<0 \cdot 01)$. After STN-DBS, the normalization of REE and the reduction in lipid and protein oxidation contribute to the restoration of weight. As levodopa decreases glucose oxidation, the reduction in daily dose of levodopa in STN-DBS-treated patients helps prevent the effect of weight gain on glycaemia.
\end{abstract}

Parkinson's disease: Resting energy expenditure: Weight change: Substrate oxidation: Diet-induced thermogenesis

Parkinson's disease (PD) results from degeneration of the basal ganglia in the brain and is characterized by tremor, bradykinesia, rigidity, and disturbances in posture and balance. The effectiveness of the pharmacologic treatments based on levodopa declines with time due to motor fluctuations and the increase in psychiatric side-effects. Weight loss often occurs in PD patients and has been described by many authors since the first report of James Parkinson (Parkinson, 1817; Vardi et al. 1976; Yapa et al. 1989; Abbott et al. 1992; Beyer et al. 1995). This may lead to undernutrition, bed sores and infectious complications (Wermuth et al. 1995). This loss of weight has been ascribed to an increased resting energy expenditure (REE) (Levi et al. 1990; Broussolle et al. 1991; Markus et al. 1992). The influence of levodopa treatment on the disturbance of body weight regulation in PD is unknown, but may be suspected as levodopa-induced dyskinesia may increase energy expenditure (Levi et al. 1990; Broussolle et al. 1991), and levodopa affects intermediary metabolism, as reflected by hyperglycaemia (Mueller \& Horwitz, 1962).

Bilateral subthalamic nucleus deep brain stimulation (STN-DBS) has been shown to be effective on both PD and motor fluctuations (Limousin et al. 1998). In common with others (Moro et al. 1999; Lopiano et al. 2001; Volkmann et al. 2001; Just \& Ostergaard, 2002; Romito et al. 2002), we noticed that STN-DBS-treated PD patients gain weight, and we were interested in the mechanism of this weight gain. The underlying energy expenditure/daily energy intake (DEI) imbalance may reflect an effect of STN-DBS on food intake, as the electrodes are implanted close to the hypothalamic centres of appetite. On the other hand, STN-DBS may influence REE: increased REE and respiratory quotient have been

\footnotetext{
Abbreviations: D-, without levodopa challenge; D+, with levodopa challenge; DEI, daily energy intake; DIT, diet-induced thermogenesis; EE, energy expenditure; FFM, fat-free mass; Gox, glucose oxidation; Group C, control group; Group L, patients on pharmacologic treatment; Group S, patients who underwent surgery; LEDD, levodopa-equivalent daily dose; Lox, lipid oxidation; NU, urinary nitrogen; PD, Parkinson's disease; Pox, protein oxidation; REE, resting energy expenditure; $\mathrm{S}-$, without stimulation; $\mathrm{S}+$, with stimulation; STN-DBS, subthalamic nucleus deep brain stimulation; TEE, total energy expenditure.

* Corresponding author: Dr Caroline Perlemoine, fax +33 0557656484, email caroline.perlemoine@chu-bordeaux.fr
} 
reported during hypothalamic electric stimulation in rodents (Atrens et al. 1987), but the effects are unknown in humans. The metabolic consequences of this weight gain may be important: reversing the weight loss in PD may seem beneficial at first sight, but it may worsen the glucose intolerance (Sandyk, 1993).

Both levodopa and STN-DBS have a dramatic acute action on clinical status, as reflected by improved motor scores a few minutes after oral ingestion of levodopa, or immediately after STN-DBS. Acute effects on REE and substrate oxidation have yet to be described, but they may contribute to a modification of body weight regulation in PD with or without STN-DBS. These actions need to be discriminated to account for the chronic influence of STNDBS on body weight, as STN-DBS-treated patients usually take lower doses of levodopa.

We therefore performed a two-step study in thirty-two patients with PD. (1) First step (comparative study between three groups): to determine the mechanism and the metabolic consequences of STN-DBS on body weight, we compared DEI, and REE in nineteen PD patients treated with STN-DBS, thirteen others treated with drugs alone and eight normal subjects. Substrate oxidation rates and plasma glucose, triglycerides and free fatty acid levels after ingestion of a test meal were also compared between the two groups of PD patients. (2) Second step (experimental study in PD patients): we determined the acute effects of STN-DBS and levodopa on REE and substrate oxidation monitored by indirect calorimetry in patients with neurostimulation switched off $(\mathrm{S}-)$ or on $(\mathrm{S}+)(n$ 19) and before $(\mathrm{D}-)$ and after $(\mathrm{D}+)$ a levodopa challenge (n 32).

\section{Patients and methods}

\section{Patients}

Thirty-two PD patients attending the Neurology clinic were studied: thirteen patients were on pharmacologic treatment (Group L) and nineteen patients underwent bilateral STNDBS (Group S), studied 13.4 $10 \cdot 1$ months after surgery. Eight normal volunteer subjects (Group C) were recruited from the Nutrition department. The main characteristics of the three groups are listed in Table 1. Control subjects were younger than the PD patients. Thus energy expenditure (EE) is expressed as joules per $\mathrm{kg}$ of fat-free mass per minute $(\mathrm{J} / \mathrm{kgFFM} / \mathrm{min})$ to correct for the potential influence of age. In healthy subjects, ageing is not associated with a modification of EE after normalization to fat-free mass (Bloesch et al. 1988). Fat-free mass was assessed by anthropometry as described in the study design. The local ethics committee of our institution approved the study and all subjects gave their written informed consent.

\section{Treatments}

The levodopa-equivalent daily dose (LEDD) was computed for each anti-PD medication by multiplying the total daily dosage of each drug by its potency relative to a standard levodopa preparation assigned the value of 1 (Table 1). LEDD was determined in PD patients at the time of the metabolic assessment. In patients who underwent surgery the pre-operative LEDD was also assessed retrospectively.

The nineteen STN-DBS-treated patients received a bilateral simultaneous STN implant using quadripolar electrodes (DBS-3389 electrode, Medtronic, Minneapolis, USA). These electrodes were connected to a subcutaneous programmable pulse generator (Itrel II or Kinetra, Medtronic) with a conventional procedure establishing the optimal functional target referenced to a line drawn from the anterior to the posterior commissure (Cuny et al. 2002).

\section{Study design}

Comparative study (chronic effects of PD and STN$D B S$ ). All participants were interviewed by a dietitian in order to determine DEI $(\mathrm{J} / \mathrm{kgFFM} / \mathrm{min})$. The diets were analysed over a period of 1 week using BILNUT IV software (Bilnut IV SOCA, Nutrisoft, Tours, France.)

All anti-PD medication was temporarily withdrawn on the evening before the measurements as the half-life of the association levodopa/benserazide is $90 \mathrm{~min}$. Basal respiratory exchanges were measured for $30 \mathrm{~min}$ starting at 09.00 hours after an overnight fast.

Table 1. Main characteristics of the three groups (Mean values with their standard errors)

\begin{tabular}{|c|c|c|c|c|c|c|}
\hline & \multicolumn{2}{|c|}{$\begin{array}{l}\text { Control subjects, } \\
\text { Group C }(n 8)\end{array}$} & \multicolumn{2}{|c|}{$\begin{array}{l}\text { PD patients on pharmacolocic } \\
\text { treatment, Group } \mathrm{L}(n 13)\end{array}$} & \multicolumn{2}{|c|}{$\begin{array}{l}\text { STN-DBS-treated PD patients, } \\
\text { Group S }(n 19)\end{array}$} \\
\hline & Mean & SEM & Mean & SEM & Mean & SEM \\
\hline Age (years) & 46 & 3.7 & $61 \cdot 5^{\mathrm{a}}$ & $10 \cdot 9$ & $59 \cdot 9^{b}$ & $6 \cdot 6$ \\
\hline Gender (males/females) & $3 / 5$ & & $8 / 5$ & & $11 / 8$ & \\
\hline $\mathrm{BMI}\left(\mathrm{kg} / \mathrm{m}^{2}\right)$ & $23 \cdot 2$ & 2.9 & $23 \cdot 1^{\mathrm{c}}$ & 4.4 & $25 \cdot 3^{\mathrm{C}}$ & $4 \cdot 3$ \\
\hline Anthropometry: fat mass (\%) & $26 \cdot 9$ & $7 \cdot 7$ & 23.8 & $7 \cdot 7$ & 26.5 & 7.6 \\
\hline Anthropometry: fat-free mass $(\mathrm{kg})$ & 47.5 & 14.4 & 49.9 & $12 \cdot 1$ & 51.6 & 11.6 \\
\hline & & Stable & -3.8 since diagnosis & $10 \cdot 0$ & +9.7 since surgery & $7 \cdot 1$ \\
\hline \multirow{2}{*}{ Levodopa equivalent dose $(\mathrm{mg} / \mathrm{d})^{\star}$} & & & 1137 & 366 & Before surgery: $1336^{d}$ & 408 \\
\hline & & & & & After surgery: $460^{\mathrm{e}}$ & 351 \\
\hline
\end{tabular}

\footnotetext{
${ }^{a} P>0.0005$ with Group C; ${ }^{b} P<0.00005$ with Group C; ${ }^{c}$ not significant with Group C; ${ }^{d}$ not significant with Group L; ${ }^{e} P<0.005$ with Group S before surgery.

*Equivalent daily doses of bromocriptine, pergolide and cabergoline are $10 \mathrm{mg}, 1 \mathrm{mg}$ and $1 \mathrm{mg}$, respectively.
} 
At noon, the patients ingested their usual dose of drugs and a test meal containing $72 \mathrm{~g}$ of carbohydrate, $32 \mathrm{~g}$ of protein and $21 \mathrm{~g}$ of lipid $(2535 \mathrm{~kJ})$, and respiratory exchanges were again assessed during $90 \mathrm{~min}$.

Experimental study (acute effects of levodopa and $S T N-D B S$ ). After the basal measurement in the morning, the patients received a levodopa challenge (Modopar dispersible: $200 \mathrm{mg}$ levodopa/50 $\mathrm{mg}$ benzerazide, Roche Neuilly Sur Seine, France) and $45 \mathrm{~min}$ later another 30 min measurement was performed (maximal concentration $1 \mathrm{~h}$ after absorption). To avoid any influence of previously ingested levodopa, all the measurements without levodopa $(\mathrm{D}-)$ were performed before the measurements with levodopa $(\mathrm{D}+)$. On the other hand, in the STNDBS-treated patients, the measurements were performed with the stimulation randomly switched 'on' or 'off' during the $\mathrm{D}-$ and then the $\mathrm{D}+$ periods, as shown in Fig. 1. Thus REE was measured in two situations in patients with pharmacologic treatment: before $(\mathrm{D}-)$ and after (D+) levodopa challenge. It was measured in four situations in the STN-DBS patients: with stimulation 'on' before levodopa challenge $(\mathrm{S}+\mathrm{D}-)$, with stimulation 'off' before levodopa challenge $(S-D-)$, with stimulation 'on' after levodopa challenge $(\mathrm{S}+\mathrm{D}+)$ and finally with stimulation 'off' after levodopa challenge $(\mathrm{S}-\mathrm{D}+)$.
The order of these four situations was allocated at random as shown in Fig. 1.

Body composition. Heights and weights of patients and controls were measured and they were asked about any changes in weight since the onset of their illness for patients on pharmacologic treatment. For the STN-DBStreated patients the data on weight evolution were available only since surgery. BMI was calculated as the ratio of weight $(\mathrm{kg})$ to the square of height $\left(\mathrm{m}^{2}\right)$. Skin-fold thickness was measured by the same investigator at four standard sites (triceps, biceps, subscapular and supra-iliac) using Harpenden callipers. Three recordings were taken from each site and the mean recorded. Body fat was estimated by the method of Durnin \& Womersley (1974). Fat-free mass was calculated as body weight less body fat.

The data are summarized in Table 1. Although BMI values were not significantly different between the three groups of subjects, weight evolution was the opposite as patients on medical treatment were losing weight and STN-DBS patients were gaining weight.

Motor scores. Unified Parkinson's Disease Rating Scale scores Fahn et al. 1987 show that levodopa challenge is efficient in improving motor scores in the two groups of PD patients (Table 2A). But in STN-DBS

Patients with medical treatment

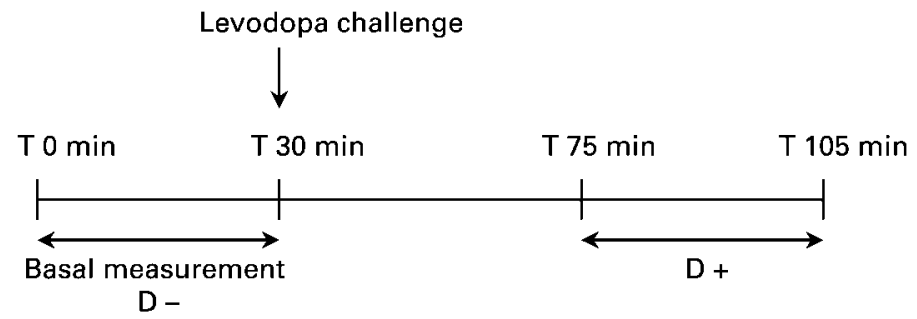

\section{$\underline{\text { STN-DBS-treated patients }}$}

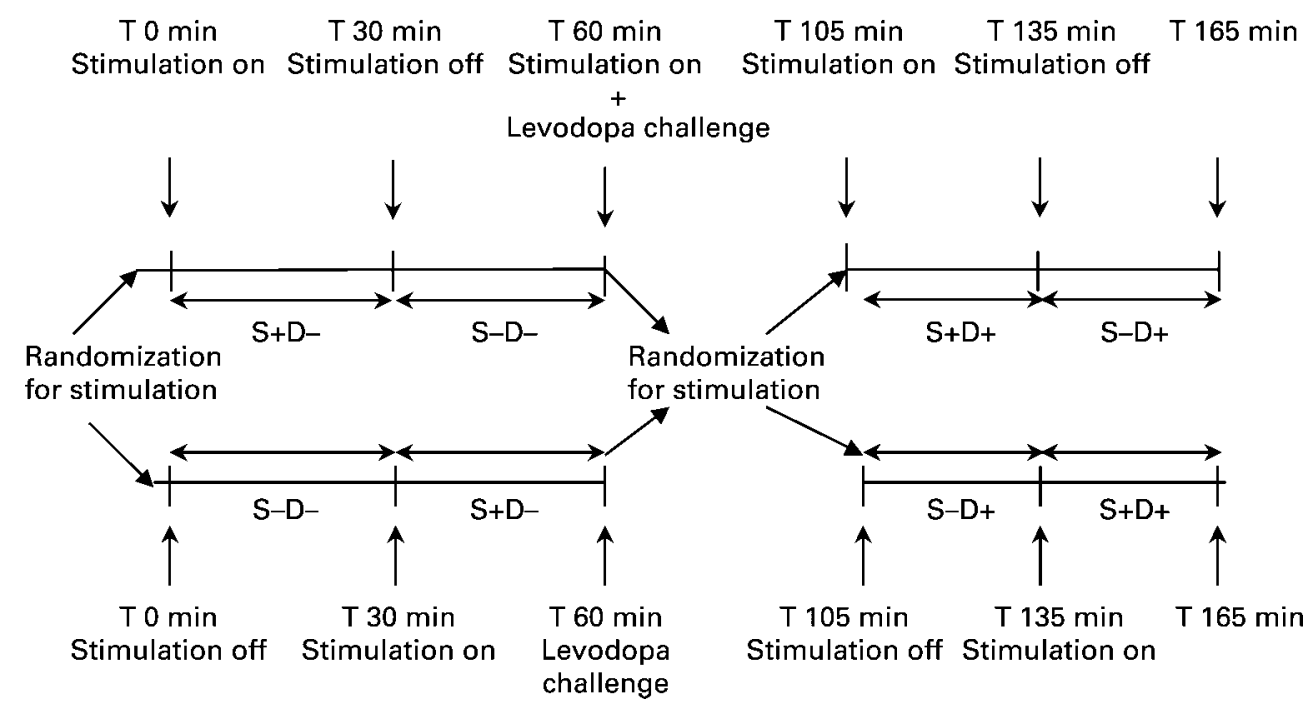

Fig. 1. Resting energy expenditure $(\mathrm{J} / \mathrm{kgFFM} / \mathrm{min})$ and substrate oxidation $(\mathrm{mg} / \mathrm{kg} / \mathrm{min})$ in patients with medical treatment or neurostimulation. 
Table 2. Effects of levodopa challenge (A) and acute effect of neurostimulation (B) on UPDRS motor scores in PD patients (Mean values with their standard errors)

\begin{tabular}{|c|c|c|c|c|c|}
\hline \multirow[b]{2}{*}{ (A) } & \multicolumn{2}{|c|}{ D- } & \multicolumn{2}{|c|}{$D+$} & \multirow[b]{2}{*}{$P$} \\
\hline & Mean & SEM & Mean & SEM & \\
\hline Group L & 36 & $16 \cdot 1$ & 15 & $7 \cdot 9$ & 0.014 \\
\hline $\begin{array}{l}\text { Group S before } \\
\text { surgery }\end{array}$ & $55 \cdot 2$ & $17 \cdot 8$ & $16 \cdot 9$ & $9 \cdot 3$ & 0.002 \\
\hline \multirow[t]{2}{*}{$P$} & \multicolumn{2}{|l|}{0.028} & \multicolumn{2}{|l|}{$>0.05$} & \\
\hline & \multicolumn{2}{|c|}{ S- } & \multicolumn{2}{|c|}{$\mathrm{S}+$} & \\
\hline (B) & Mean & SEM & Mean & SEM & $P$ \\
\hline D- & $50 \cdot 3$ & $13 \cdot 6$ & $19 \cdot 8$ & $9 \cdot 3$ & 0.002 \\
\hline $\begin{array}{l}\mathrm{D}+ \\
P\end{array}$ & $22 \cdot 1$ & $2 \cdot 11$ & $10 \cdot 8$ & $6 \cdot 4$ & 0.01 \\
\hline$P$ & 0.003 & & 0.002 & & \\
\hline
\end{tabular}

$\mathrm{D}-$, without levodopa challenge; $\mathrm{D}+$, with levodopa challenge; $\mathrm{S}-$, without stimulation; $\mathrm{S}+$, with stimulation.

patients the acute effect of neurostimulation is much more important (Table 2B).

Indirect calorimetry. REE was measured by indirect calorimetry using a ventilated hood technique in which subjects lay on a bed with their head and shoulders within the hood (Delatrac Metabolic Monitor; Datex, Helsinki, Finland). Values for EE and substrate oxidation rates were calculated from respiratory exchange measurements over 30 min sessions using standard equations (Ferrannini, 1988):

$$
\begin{gathered}
\text { Gox }=4 \cdot 55 \mathrm{~V}_{\mathrm{CO} 2}-3 \cdot 21 \mathrm{~V}_{\mathrm{O} 2}-2 \cdot 87 \mathrm{NU} \\
\mathrm{Lox}=1 \cdot 67\left(\mathrm{~V}_{\mathrm{O} 2}-\mathrm{V}_{\mathrm{CO} 2}\right)-1 \cdot 92 \mathrm{NU} \\
\mathrm{Pox}=6 \cdot 25 \mathrm{NU} \\
\mathrm{EE}=3 \cdot 91 \mathrm{~V}_{\mathrm{O} 2}+1 \cdot 10 \mathrm{~V}_{\mathrm{CO} 2}-3 \cdot 34 \mathrm{NU}
\end{gathered}
$$

where Gox is glucose oxidation, Lox is lipid oxidation, Pox is protein oxidation and NU is urinary nitrogen.

The values of glucose, lipid and protein oxidations are also expressed as percentage of energy expenditure in the fasting state (Ferrannini, 1988).

Analytical procedures. Fasting blood samples were collected on lithium heparinate Vacutainers (BD Vacutainers Systems, Plymouth, UK) at the end of each measurement session and 30 and 90 min after the ingestion of the test meal. Glycaemia (Olympus America, OSR 6121, Rungis, France), insulinaemia (INSI-CTK IRMA, DiaSorin S.A., Antony, France), C peptide (C peptide IRMA, DiaSorin S.A.), triacylglycerols (Olympus America) and free fatty acids (Kit Nefac, Waco Chemicals, Neuss, Germany) were determined.

Urinary samples were collected before lunch to calculate protein oxidation in the fasting state, which was assumed to be the same during all the acute study, and at the end of the test $(2 \mathrm{~h}$ postprandial) to calculate postprandial protein oxidation

NU was defined as the sum of urinary urea, creatinine and uric acid (Rigalleau et al. 1997), determined using rou- tine, semi-automated methods:

$$
\begin{aligned}
\mathrm{NU}(\mathrm{mmol} / \mathrm{min}) & =\left(2 \times \mathrm{U}_{\text {urea }}\right) \\
& +\left(3 \times \mathrm{U}_{\mathrm{cr}}\right)+\left(4 \times \mathrm{U}_{\text {uric acid }}\right)
\end{aligned}
$$

Statistical analysis and expression of results

Results are shown as means with their standard errors represented by vertical bars. Comparisons were performed by ANOVA followed by paired or unpaired $t$ tests. For indirect calorimetry results (energy expenditure and substrate oxidation rates), we did not assume a normal distribution of these parameters in the PD population, non-parametric tests were therefore used (Mann-Witney test for paired data and Wilcoxon signed rank test for unpaired data). $P<0.05$ was considered significant.

\section{Results}

Comparative study (chronic effects of PD and STN-DBS)

Fasting state. Resting energy expenditure (Fig. 2): REE was increased in patients on pharmacologic treatment in comparison with controls (L (D-): 102.9 (SEM 21.3) $\mathrm{J} / \mathrm{kgFFM} / \min v$. C: 88.3 (SEM 12.5); $+16.5 \%, P<0.01$ ) and with patients who underwent surgery (L $(\mathrm{D}-)$ : $102 \cdot 9$ (SEM 21.3) $\mathrm{J} / \mathrm{kgFFM} / \mathrm{min} \quad v$. S (D-): 88.3 (SEM 10.5); $+16.5 \%, P<0.001)$. Thus, in Group S, REE was normal in comparison with control subjects.
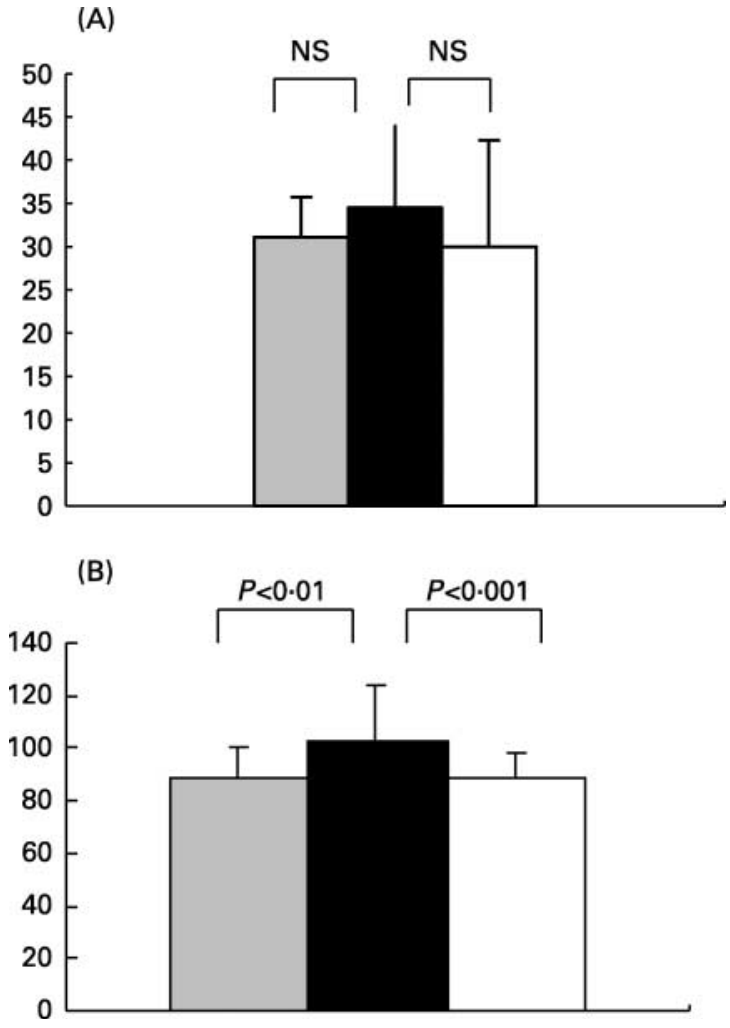

Fig. 2. Daily energy intake $(\mathrm{J} / \mathrm{kgFFM} / \mathrm{min})(\mathrm{A})$ and resting energy expenditure $(\mathrm{J} / \mathrm{kgFFM} / \mathrm{min})(\mathrm{B})$ in the three groups: control subjects $(\square)$, patients on pharmacologic treatment $(\square)$ and STN-DBS-treated patients $(\square)$. 
STN-DBS patients oxidized more glucose (S: $1 \cdot 16$ (SEM $0.63) \mathrm{mg} / \mathrm{kg} / \mathrm{min} v$. L: 0.64 (SEM 0.86$) ;+81 \%, P<0.05)$, less lipids (S: 0.90 (SEM 0.38) v. L: 1.24 (SEM 0.52) mg/kg/ $\min ;-27 \%, P<0.05)$ and less protein (S: 0.57 (SEM 0.19) v. L: 1.05 (SEM 0.94$) \mathrm{mg} / \mathrm{kg} / \mathrm{min} ;-46 \%, P<0.05)$ than did the drug-treated patients. Substrate oxidations in controls subjects were $1.2($ SEM 0.36$) \mathrm{mg} / \mathrm{kg} / \mathrm{min}$ for glucose, 0.6 (SEM 0.35$) \mathrm{mg} / \mathrm{kg} / \mathrm{min}$ for lipids and 0.64 (SEM 0.2) $\mathrm{mg} / \mathrm{kg} /$ min for protein.

Glucose oxidation represents $28.5 \%$ (SEM 24.4) of REE in STN-DBS patients $v .13 \%$ (SEM 26.8) in drug-treated patients $(P<0.05)$.

Lipids oxidation represents $56.2 \%$ (SEM 37.4) of REE in STN-DBS patients $v .63 .7 \%$ (SEM 41.4) in drug-treated patients $(P<0.05)$.

Protein oxidation represents $15 \cdot 3 \%$ (SEM 38.2) of REE in STN-DBS patients $v .23 \cdot 3 \%$ (SEM 32.1) in drug-treated patients $(P<0 \cdot 05)$.

Fasting glycaemia, triacylglycerols and free fatty acids were normal in PD patients.

Daily energy intake (Fig. 2). Although the differences were not significant, patients receiving pharmacologic treatment tended to have higher DEI in comparison with controls (L: 34.5 (SEM 10.8) v. C: 31.1 (SEM 4.6) $\mathrm{J} / \mathrm{kgFFM} / \mathrm{min}$ ) and with patients who underwent surgery (S: 30 (SEM 12.3) J/kgFFM/min).

Effects of test meals (Fig. 3). After the test meal, EE remained higher in Group L in comparison with Group S, although the difference was not as significant as it was during the fasting state. EE in Group L did not rise significantly in the postprandial state (postprandial: 102.9 (SEM 15.5) $v$. fasting (D+): 99.5 (SEM 28.0) J/kgFFM/min, $+3.36 \%$; NS): the diet-induced thermogenesis (DIT) was virtually abolished in the patients on pharmacologic treatment. In Group S, EE rose normally after the ingestion of the test meal (postprandial: 96.4 (SEM 16.3) $v$. fasting $(\mathrm{D}+): \quad 84.5 \quad(\mathrm{SEM} 10.2) \quad \mathrm{J} / \mathrm{kgFFM} / \mathrm{min}, \quad+14.1 \%$; $P<0 \cdot 01)$ : DIT was restored.

The variations in nutrient oxidation did not differ between the two groups of patients: lipid and protein oxidations fell and glucose oxidation rose. The rise in blood glucose and triacylglycerols and the fall in free fatty acids did not differ between the two groups of patients.

\section{Experimental study (acute effects of levodopa and electrostimulation)}

Acute effects of levodopa (n 32, Fig. 4). The results of three of the thirteen patients on pharmacologic treatment were analysed separately, as their levodopa challenge induced marked dyskinesia. In these three patients, REE rose dramatically after levodopa challenge (D+: 135.4 (SEM 30.9) J/kgFFM/min v. D-: 93.7 (SEM 18.4); + $45 \%$, $P<0.05)$.

For the other subjects ( $n$ 29), the levodopa challenge led to a moderate reduction of REE (D+: 91.6 (SEM 21.6) $\mathrm{J} / \mathrm{kgFFM} / \min v$. D-: 99.9 (SEM 27.3); $-8.3 \%, P<0.05)$.

Glucose oxidation fell (D+: 0.73 (SEM 0.27) $v$. D-: 1.16 (SEM 0.52) $\mathrm{mg} / \mathrm{kg} / \mathrm{min} ;-37 \%, P<0.01$ ) and lipid oxidation was unchanged (D+: 1.15 (SEM 0.37) v. D-: $1.12($ SEM 0.41$) \mathrm{mg} / \mathrm{kg} / \mathrm{min} ;+2.7 \%$, NS). These effects

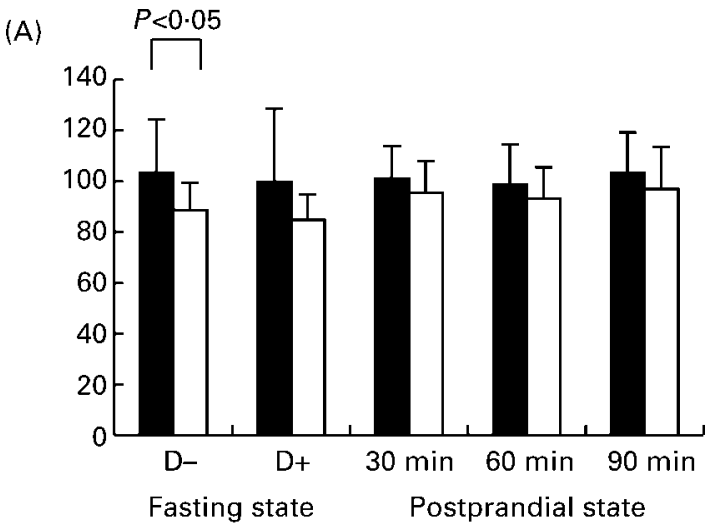

(B)
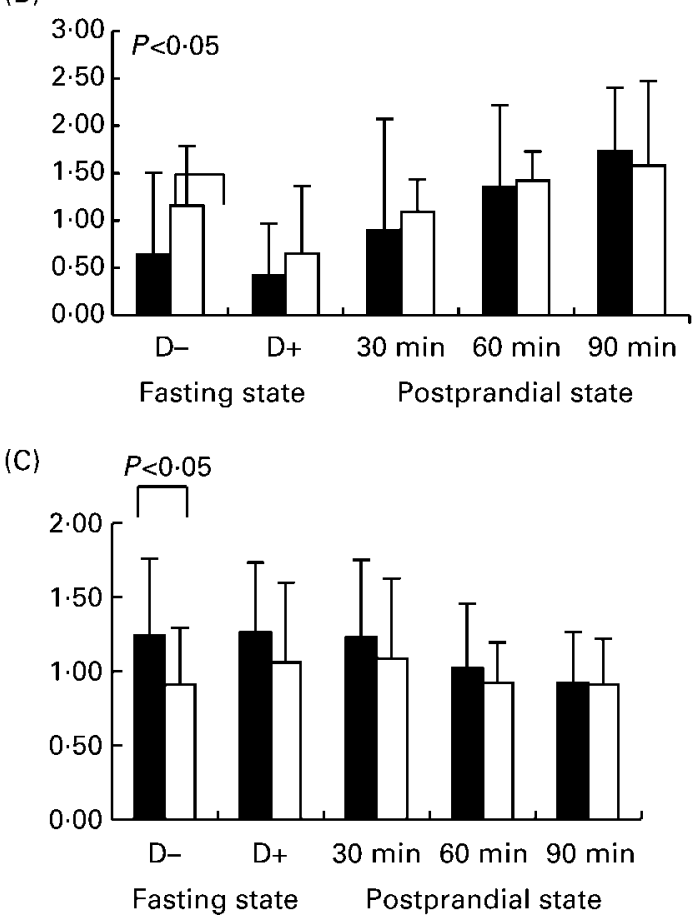

Fig. 3. Energy expenditure $(\mathrm{J} / \mathrm{kgFFM} / \mathrm{min})(\mathrm{A})$, glucose oxidation ( $\mathrm{mg} / \mathrm{kg} / \mathrm{min}$ ) (B) and lipid oxidation ( $\mathrm{mg} / \mathrm{kg} / \mathrm{min})$ (C) in fasting (before and after levodopa challenge) and postprandial states (at 30,60 and $90 \mathrm{~min}$ ) in PD patients. (ם), Patients on pharmacologic treatment; $(\square)$, STN-DBS-treated patients with stimulation on.

were similar in patients with STN-DBS ( $n$ 19) and in patients on pharmacologic treatment who did not experience dyskinesia ( $n$ 10).

Protein oxidation was not calculated after the levodopa challenge because urine samples were not available.

There was a small but consistent rise in fasting glycaemia after levodopa challenge in the two groups of patients (Group S: D+: 5.5 (SEM 1.2) mmol/1 v. D- : 5.4 (SEM 1.5), NS; Group L: D+: 5.6 (SEM 0.8) $\mathrm{mmol} / 1$ v. D-: $5 \cdot 3$ (SEM $0 \cdot 6), P<0 \cdot 01)$.

Acute effects of electrostimulation (n 19, Fig. 5). REE felt immediately and dramatically (S+: 86.6 (SEM 10.4) $\mathrm{J} / \mathrm{kgFFM} / \mathrm{min}$ v. S-: 104.9 (SEM 30.9); $-17.5 \%$, $P<0.01)$ after starting STN-DBS.

Glucose oxidation was not affected ( $\mathrm{S}+:$ 1.00 (SEM $0.45)$ v. $\mathrm{S}-: 0.90(\mathrm{SEM} 0.40) \mathrm{mg} / \mathrm{kg} / \mathrm{min} ; \mathrm{NS})$, whereas 
(A)

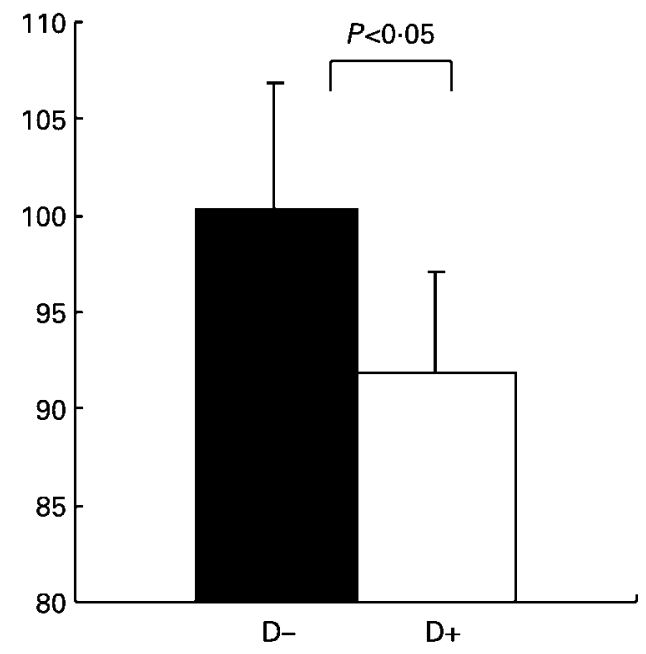

(B)

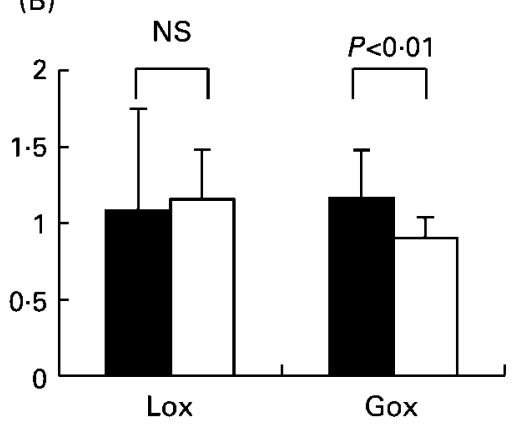

Fig. 4. STN-DBS-treated patients with stimulation on: acute effects of levodopa on resting energy expenditure $(\mathrm{J} / \mathrm{kgFFM} / \mathrm{min})(A)$ and lipid oxidation (Lox; $\mathrm{mg} / \mathrm{kg} / \mathrm{min}$ ) and glucose oxidation (Gox; $\mathrm{mg} / \mathrm{kg} / \mathrm{min}$ ) (B). $\square$, Before levodopa challenge; $\square$, after levodopa challenge.

lipid oxidation was reduced ( $\mathrm{S}+: 0.98(\mathrm{SEM} 0.29) \mathrm{mg} / \mathrm{kg} /$ min v. S-: 1.30 (SEM 0.49); $-24 \%, P<0.001)$.

Fasting blood glucose levels fell slightly but significantly when STN-DBS was switched on (S+: 5.4 (SEM 1.4) $\mathrm{mmol} / \mathrm{l} v$. S- : 5.5 (SEM 1.3); $P<0 \cdot 01)$.

\section{Discussion}

The hypothalamus is known to play a central role in the regulation of body weight (Jéquier \& Tappy, 1999). It responds to hormonal and pharmacological influences, and animal studies have shown it to be responsive to electrostimulation (Atrens et al. 1987). The recent reports of weight gain in PD patients treated by STN-DBS have therefore raised several intriguing questions. Is it due to an effect on appetite and food intake, or to a reduction of the increased EE in PD patients? Does STN-DBS have a direct action or is it the result of the reduction in levodopa doses? What are the metabolic consequences of STN-DBS?

The results of our study are in favour of an effect of STN-DBS on energy expenditure. REE has been found to be increased in patients on long-term treatment with levodopa as compared to healthy controls, whereas it was normal in STN-DBS-treated patients (Levi et al. 1990;
(A)

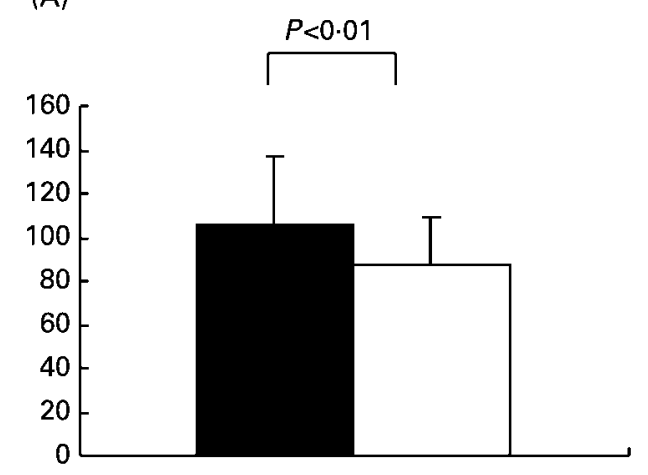

(B)

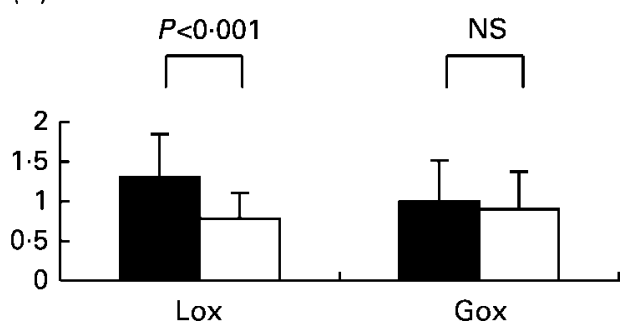

Fig. 5. STN-DBS-treated patients: acute effects of stimulation on resting energy expenditure $(\mathrm{J} / \mathrm{kgFFM} / \mathrm{min})(\mathrm{A})$ and lipid oxidation (Lox; $\mathrm{mg} / \mathrm{kg} / \mathrm{min}$ ) and glucose oxidation (Gox; $\mathrm{mg} / \mathrm{kg} / \mathrm{min}$ ) (B). With stimulation off; $\square$, with stimulation on.

Broussolle et al. 1991; Markus et al. 1992). We show that this normalization of REE results from an acute effect of the electrostimulation: switching 'on' STN-DBS in these patients produced a prompt equivalent reduction in $\operatorname{REE}(-17.5 \%)$. Although the mechanism of this action is not known, we surmized an influence on muscular tone and activity. Hypothalamic electrostimulation in muscle-relaxed rats leads to an increased respiratory quotient as we found, but this increases their energy expenditure (Atrens et al. 1987). This discrepancy may stem from a difference in electrode placement or interspecies differences. The normalization of REE, and the reduction in lipid and protein oxidation as compared to levodopa-treated patients, were assumed to contribute to the weight gain during the first months after surgery. The expression of substrate oxidations in percentage of REE shows that their modification is independent of the variations of energy expenditure.

On the other hand, the DEI did not significantly differ between STN-DBS-treated patients, levodopa-treated patients and healthy controls. The highest DEI were in our levodopa-treated patients, as has been reported by others (Chen et al. 2003). We are not aware of any reports on DEI in STN-DBS-treated patients. High DEI in levodopa-treated patients losing weight and low DEI in STNDBS-treated patients gaining weight suggest that energy intake is not the main contributor to the weight change. However, the inaccuracy of self-reported intakes should prompt caution in the interpretation of this result. We do not exclude a regional effect of PD degenerative lesions or STN-DBS on hypothalamic satiety centres and the reduction in REE may not be the sole explanation for the 
differential changes in body weight between STN-DBSand levodopa-treated patients.

Nevertheless, REE is only one of the three components of total energy expenditure (TEE) that also comprises diet-induced thermogenesis (DIT) and energy expenditure related to physical activity.

DIT was virtually absent in our drug-treated patients but was restored to normal values after STN-DBS (Jéquier \& Schutz, 1988). This effect did not compensate for the reduction in REE: postprandial EE was still higher in drug-treated patients than after STN-DBS. DIT depends on the nutrient content of the meal, which was the same in all patients: total ingestion of the test meal was verified. On the other hand, the patients ingested their usual dopamine dose at the beginning of the meal, whereas most of the STN-DBS patients had stopped lunch-time dopamine for several months: the difference in dopamine intake may explain the difference in postprandial EE. Further studies are necessary to test this hypothesis. Because DIT has a sympathetic component (Acheson et al. 1984), the altered DIT may stem from the sympathetic nervous system impairment in PD (Langston \& Forno, 1978). Further studies will be needed to demonstrate that such impairments are corrected by STN-DBS.

STN-DBS may also promote weight gain by reducing EE related to physical activity. Using dideuterated water to study PD patients without electrostimulation in free-living conditions, Toth et al. (1997) noted a reduction in TEE, and suggested that it reflected a reduction in energy expenditure related to physical activity. A further reduction by STN-DBS seems unlikely as this treatment improves motor scores and physical capacity of the patients, but it may also reduce the energy cost of physical activity. More studies will be required to assess TEE and EE related to physical activity in PD patients, and the influence of STN-DBS in free-living conditions. It is worth noting that the reductions of about $14.6 \mathrm{~J} / \mathrm{kgFFM} / \mathrm{min}$ for REE or $0.34 \mathrm{mg} / \mathrm{kg} / \mathrm{min}$ for lipid oxidation we observed are consistent with the $1 \mathrm{~kg} / \mathrm{month}$ body weight gain observed in our patients.

We also found a significant action of levodopa during our experimental study. The levodopa challenge led to a moderate reduction in REE ( $-8.3 \%$ : half that of switching 'on' STN-DBS), which is consistent with another report (Levi et al. 1990). Although this may help these patients avoid weight loss, it was not sufficient in our patients: their REE in the fasting state was $16.5 \%$ higher than normal, and they were losing weight. Moreover, dopamine-induced dyskinesia had a deleterious effect on REE $(+45 \%)$ in three drug-treated patients. Levodopa also dramatically reduced glucose oxidation $(-37 \%)$, with a slight but consistent hyperglycaemic effect, as noted by other workers (Mueller \& Horwitz, 1962). The immediate reduction in glucose oxidation after dopamine ingestion is likely to be an important contributor to the rise in plasma glucose. Levodopa-induced hyperglycaemia may contribute to the high incidence of glucose intolerance in this population of patients (Sandyk, 1993) and weight gain would worsen these metabolic disturbances. To our knowledge, diabetes has not yet been reported in STNDBS-treated PD patients. Our findings suggest that the reduction in LEDD may protect them.
In summary, we found a marked reduction in REE, lipid and protein oxidation in STN-DBS-treated PD patients as compared to patients on drug therapy. These effects were reproduced by switching 'on' the stimulation. They contribute to the gain in weight of these patients, which may be regarded as favourable as no deleterious effects on plasma glucose or triglycerides were detected. Several studies have shown that poor nutritional status, as indicated by low muscle bulk and fat stores, is an important predictor of mortality in the general population (Campbell et al. 1990). On the other hand, some patients may become overweight or even obese if they continue to gain weight over the ensuing years. Further prospective studies will be necessary to determine the evolution and the composition of this weight gain and have begun in our institution. Although levodopa reduced REE, the action was less pronounced, and was not sufficient to prevent weight loss. In fact REE was increased after the levodopa challenge in some patients due to dyskinesia. It was associated with a reduction in glucose oxidation, and a slight hyperglycaemic effect that may contribute to the glucose intolerance in many PD patients. The reduction in levodopa doses was thought to protect STN-DBS patients from any further hyperglycaemia with weight gain.

\section{Acknowledgements}

The authors acknowledge S. P. Jarman for translation of the paper.

\section{References}

Abbott RA, Cox M, Markus H \& Tomkins A (1992) Diet, body size and micronutrient status in Parkinson's disease. Eur $J$ Clin Nutr 46, 879-884.

Acheson KJ, Ravussin E, Wahren J \& Jéquier E (1984) Thermic effect of glucose in man: obligatory and facultative thermogenesis. $J$ Clin Invest 74, 1572-1580.

Atrens DM, Siviy SM, Holmes LJ, Solowij N \& Jirasek M (1987) Hypothalamic modulation of thermogenesis and energy substrate utilization. Brain Res Bull 18, 303-308.

Beyer PL, Palarino MY, Michalek D, Busenbark K \& Koller WC (1995) Weight change and body composition in patients with Parkinson's disease. J Am Diet Assoc 95, 979-983.

Bloesch D, Schutz Y, Breitenstein E, Jéquier E \& Felber JP (1988) Thermogenic response to an oral glucose load in man: comparison between young and elderly subjects. $\mathrm{J} \mathrm{Am} \mathrm{Coll}$ Nutr 7, 471-483.

Broussolle E, Borson F, Gonzalez de Suso JM, Chayvialle JA, Beylot M \& Chazot G (1991) Increase of energy expenditure in Parkinson's disease. Rev Neurol 147, 46-51.

Campbell AJ, Spears GFS, Brown JS, Busby WJ \& Borrie MJ (1990) Anthropometric measurements as predictors of mortality in a community population aged 70 years and over. Age Ageing 19, $131-135$.

Chen H, Zhang SM, Hernán MA, Willet WC \& Ascherio A (2003) Weight loss in Parkinson's disease. Ann Neurol 53, 676-679.

Cuny E, Guehl D, Burbaud P, Gross C, Dousset V \& Rougier A (2002) Lack of agreement between direct magnetic resonance imaging and statistical determination of a subthalamic target: the role of electrophysiological guidance. J Neurosurg 97, 591-597.

Durnin JVGA \& Womersley J (1974) Body fat assessed from 
total body density and its estimation from skinfold thickness: measurements on 481 men and women aged from 16 to 72 years. Br J Nutr 32, 77-97.

Fahn S, Elton RL \& members of the UPDRS Development Committee (1987) The unified Parkinson's disease rating scale. In Recent Developments in Parkinson's Disease, vol. 2, pp. 153-163, 293-304 [S Fahn, CD Marsden, DB Calne and M Goldstein, editors]. New Jersey: Macmillan Healthcare Information.

Ferrannini E (1988) The theoretical bases of indirect calorimetry: a review. Metabolism 37, 287-301.

Jéquier E \& Schutz Y (1988) Energy expenditure in obesity and diabetes. Diabetes/Metab Rev 4, 583-593.

Jéquier E \& Tappy L (1999) Regulation of body weight in humans. Physiol Rev 79, 451-480.

Just H \& Ostergaard K (2002) Health-related quality of life in patients with advanced Parkinson's disease treated with deep brain stimulation of the subthalamic nuclei. Mov Disord 17, 539-545.

Langston JW \& Forno LS (1978) The hypothalamus in Parkinson disease. Ann Neurol 3, 129-133.

Levi S, Cox M, Lugon M, Hodkinson M \& Tomkins A (1990) Increased energy expenditure in Parkinson's disease. $\mathrm{Br} \mathrm{Med}$ $J$ 301, 1256-1257.

Limousin P, Krack P, Pollak P, Benazzowz A, Ardorin C, Hoffmann D \& Benabid AL (1998) Electrical stimulation of the subthalamic nucleus in advanced Parkinson's disease. $N$ Engl J Med 339, 1105-1111.

Lopiano L, Rizzone M, Bergamasco B, Tavella A, Torre E, Perozzo P, Valentini MC \& Lanotte M (2001) Deep brain stimulation of the subthalamic nucleus: clinical effectiveness and safety. Neurology 56, 552-554.

Markus HS, Cox M \& Tomkins AM (1992) Raised resting energy expenditure in Parkinson's disease and its relationship to muscle rigidity. Clin Sci (Lond) 83, 199-204.
Moro E, Scerrati M, Romito LM, Roselli R, Tonali P \& Albanese A (1999) Chronic subthalamic nucleus stimulation reduces medication requirements in Parkinson's disease. Neurology 53, 85-90.

Mueller PS \& Horwitz D (1962) Plasma free fatty acid and blood glucose responses to analogues of norepinephrine in man. $J$ Lipid Res 3, 251-255.

Parkinson J (1817) An Essay on the Shaking Palsy. London: Whittingham and Bowland.

Rigalleau V, Combe C, Blanchetier V, Aubertin J, Aparicio M \& Gin H (1997) Low protein diet in uremia: effects on glucose metabolism and energy production rate. Kidney Int 51, $1222-1227$.

Romito LM, Scerrati M, Contarino MF, Bentivoglio AR, Tonali P \& Albanese A (2002) Long-term follow up of subthalamic nucleus stimulation in Parkinson's disease. Neurology 58, $1546-1550$.

Sandyk R (1993) The relationship between diabetes mellitus and Parkinson's disease. Int J Neurosci 69, 125-130.

Toth MJ, Fishman PS \& Poehlman ET (1997) Free-living daily energy expenditure in patients with Parkinson's disease. Neurology 48, 88-91.

Vardi J, Oberman Z, Rabey I, Streifler M, Ayalon D \& Herzberg M (1976) Weight loss in patients treated long-term with levodopa. J Neurol Sci 30, 33-40.

Volkmann A, Allert N, Voges J, Weiss PH, Freund HJ \& Sturm V (2001) Safety and efficacy of pallidal or subthalamic nucleus stimulation in advanced PD. Neurology 56, 548-551.

Wermuth L, Stenager EN, Stenager E \& Boldsen J (1995) Mortality in patients with Parkinson's disease. Acta Neurol Scand 92, 55-58.

Yapa RS, Playfer JR \& Lye M (1989) Anthropometric and nutritional assessment of elderly patients with Parkinson's disease. $J$ Clin Exp Gerontol 11, 155-164. 